\title{
Welcome to Future Medicinal Chemistry volume 10
}

\author{
Benjamin Walden*,1 \\ ${ }^{1}$ Future Science Group, Unitec House, 2 Albert Place, London N3 1QB, UK \\ * Author for correspondence: b.walden@future-science.com
}

First draft submitted: 10 November 2017; Accepted for publication: 10 November 2017; Published online: 15 December 2017

Keywords: drug design • medicinal chemistry • research

We would like to welcome our readers to Volume 10 of Future Medicinal Chemistry! In this foreword, we will be taking a look at some of the highlights from the journal over the last 12 months, as well as what there is to expect in the coming year.

We also want to take this opportunity to thank our editorial board members, authors, peer reviewers and readers for their continued support; and we look forward to working with all our contributors again in 2018.

\section{Demographics}

Over the past year, Future Medicinal Chemistry's readership has continued to expand. While the majority of our audience is from Europe and North America, there is an increasing proportion of readers from Asia (Figure 1). While we have seen a steady number of subscribers from academic backgrounds, the journal is also drawing in subscribers from a number of other institutions (Figure 2).

Our authorship also continues to change. With the majority of authors coming from Europe and Asia, we are also seeing a rise in accepted submission from African nations and institutions in the Middle East (Figure 3).

\section{Content highlights of 2017 \\ Trends}

2017 saw the emergence of some new themes of interest in Future Medicinal Chemistry. A number of computational studies were well received, ranging from docking studies on complex systems to the role of big data and learning systems in drug design [1]. Articles discussing novel target domains for drugs also received significant interest, including epigenetic structures, faulty signaling pathways and domains showing significant variation [2].

\section{Research}

At the time of writing, our most cited research article was the paper 'Active learning for computational chemogenomics', by James Bentley Brown (University of Birmingham) and colleagues. The paper detailed product screening for compound-protein interaction, through an active learning method (Random Forest) [1].

Review articles also attracted interest, including 'Selectivity on-target of bromodomain chemical probes by structure-guided medicinal chemistry and chemical biology', by Alessio Ciulli and Carles Galdeano (University of Dundee), which discussed new target functionalities for drugs on epigenetic proteins [2]; and 'Pseudokinases: update on their functions and evaluation as new drug targets', by Dominic Byrne and colleagues (University of Liverpool), looking at another set of potential drug targets [3].

\section{Editorial style content}

Future Medicinal Chemistry also saw several shorter articles attracting attention. 'The road to avibactam: the first clinically useful non- $\beta$-lactam working somewhat like a $\beta$-lactam', by David Yuxin Wang, Martine I Abboud, Marios S Markoulides, Jürgen Brem and Christopher J Schofield (University of Oxford), reviewed the history of artificial antibiotics and the development of their modes of action [4]. 

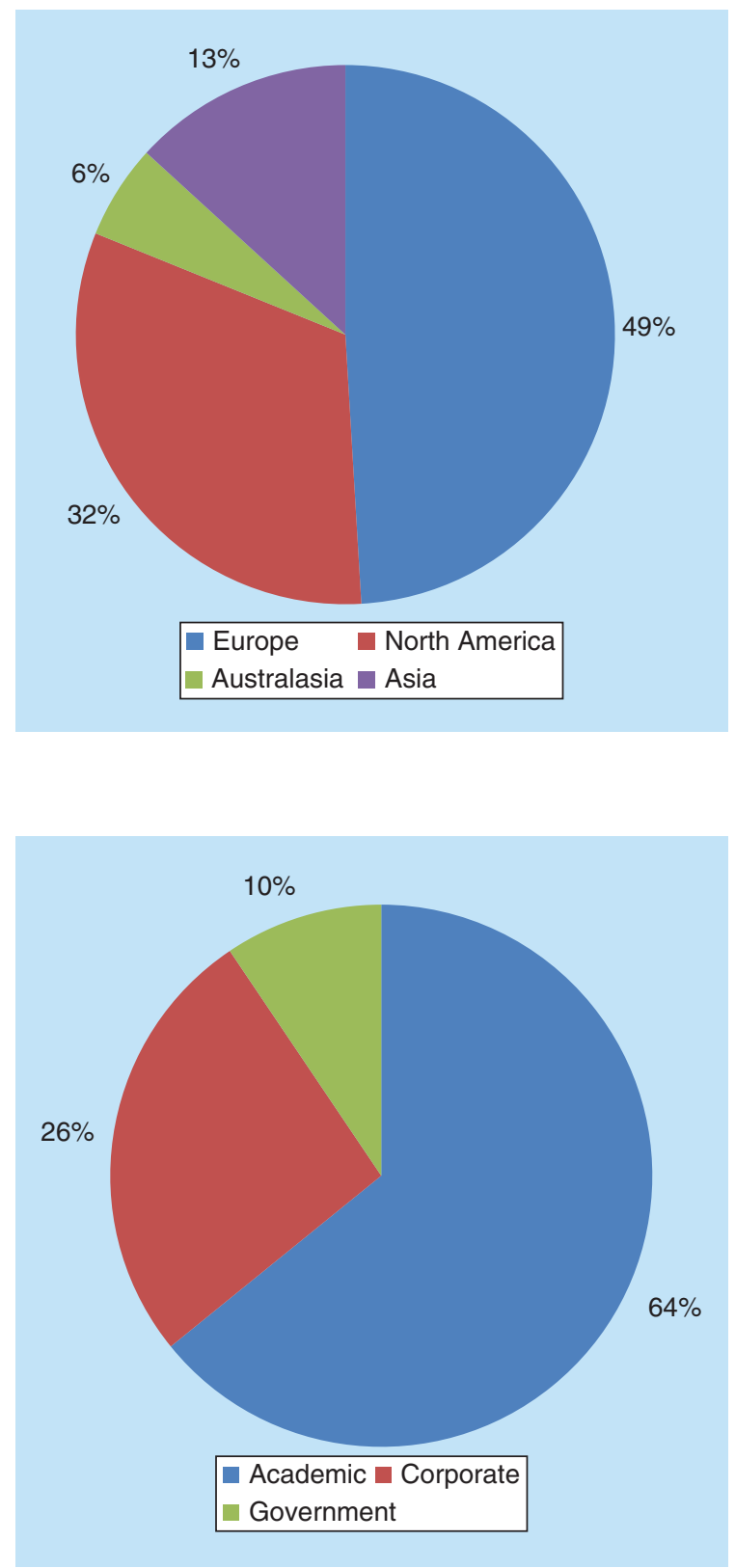

Figure 1. Percentage subscriptions by geographical location.

Figure 2. Percentage subscriptions by sector.

Capturing the current Zeitgeist, the editorial 'Does 'big data' exist in medicinal chemistry, and if so, how can it be harnessed?', by Igor V Tetko (German Research Center for Environmental Health) and colleagues, discussed the demand for big data approaches for virtual chemical spaces and the limitation of learning systems [5].

Another, the editorial by Carles Galdeano (University of Barcelona), 'Drugging the undruggable: targeting challenging E3 ligases for personalized medicine', took on another tough drug target, discussing the challenges provided by E3 variation and potential for higher specificity [6].

\section{Special focus issues}

This year, the journal also saw the publication of themed issues, which took a closer look at topical areas within medicinal chemistry. In May, volume 9, issue 8, entitled 'Advances in neurodegenerative disease therapy', was guest edited by Maria Laura Bolognesi (University of Bologna), with a second part released in June. The double issue focused on reviewing the guidelines and hurdles for developing second generation, multi-target drugs for neurodegenerative disease and the different approaches to Alzheimer's drug design [7]. 
Figure 3. Percentage authorship by geographic location.

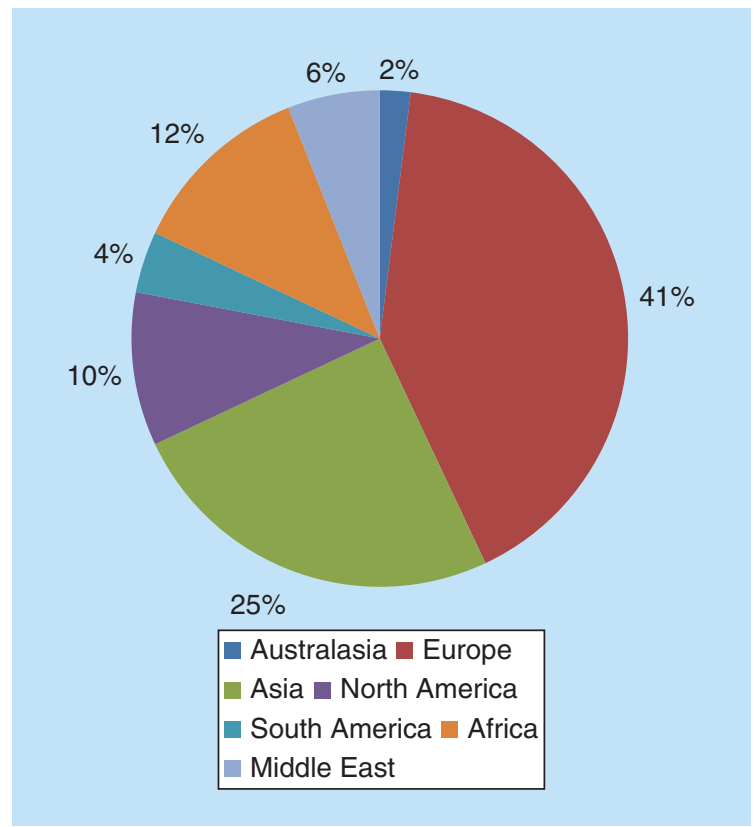

A second special focus issue was published in July for volume 9, issue 12. This was focused on 'immunotherapy', was guest edited by Antonio Macchiarulo (Università degli Studi di Perugia), and looked at new methods for curbing immune responses, as well as the challenges in building effective human models for trialing immunotherapeutic drugs [8].

Looking forward to 2018, we have a number of new focus issues planned, covering themes on metallodrugs as new antitumor complexes, and on computational chemistry's role in drug design.

\section{Article outreach \& online presence}

Future Medicinal Chemistry continues to be active across social media, and we are keen for you to engage. Follow our latest updates on LinkedIn [9] and at @fsgfmc on Twitter [10], including regular journal highlights and the latest medicinal chemistry news.

We also recommend you to get involved through our partnered digital site, MedChemNet [11], which provides an interactive resource to engage with the scientific field. The site posts regular updates on developments in medicinal chemistry, and is a platform for experts to share their knowledge and opinions, as well as get involved in the medicinal chemistry debate.

\section{Conclusion}

We appreciate all the feedback that has been provided over the last year as to the direction of the journal and look forward to more in the year to come. We are keen for you to submit any unsolicited articles to the journal, should they be research, opinion or review. If you have a submission you would like for us to consider, you can find details on article preparation or submission online [12] or get in touch.

Finally we would like to thank everyone for your continued engagement and support and we look forward to working with all of you over the coming year.

\section{Financial \& competing interests disclosure}

B Walden is an employee of Future Science Ltd. The author has no other relevant affiliations or financial involvement with any organization or entity with a financial interest in or financial conflict with the subject matter or materials discussed in the manuscript apart from those disclosed.

No writing assistance was utilized in the production of this manuscript. 


\section{References}

1 Reker D, Schneider P, Schneider S, Brown JB. Active learning for computational chemogenomics. Future Med. Chem. 9(4), 381-402 (2017).

2 Galdeano C, Ciulli A. Selectivity on-target of bromodomain chemical probes by structure-guided medicinal chemistry and chemical biology. Future Med. Chem. 8(13), 1655-1680 (2016).

3 Byrne D, Foulkes D, Eyers P. Pseudokinases: update on their functions and evaluation as new drug targets. Future Med. Chem. 9(2), 245-265 (2017).

4 Wang DY, Abboud M, Markoulides M, Brem J, Schofield C. The road to avibactam: the first clinically useful non- $\beta$-lactam working somewhat like a $\beta$-lactam. Future Med. Chem. 8(10), 1061-1082 (2016).

5 Tetko I, Engkvist O, Chen H. Does 'big data' exist in medicinal chemistry, and if so, how can it be harnessed? Future Med. Chem. 8(15), 1801-1806 (2016).

6 Galdeano C. Drugging the undruggable: targeting challenging E3 ligases for personalized medicine. Future Med. Chem. 9(4), 347-350 (2017).

7 Bolognesi ML. Neurodegenerative drug discovery: building on the past, looking to the future. Future Med. Chem. 9(8), 707-709 (2017).

8 Macchiarulo A. Immunotherapy. . a a pursuit race to tomorrow's medicines. Future Med. Chem. 9(12), 1297-1299 (2017).

9 Future Medicinal Chemistry, Linkedin group. https://www.linkedin.com/groups/2822505

10 Future Medicinal Chemistry, Twitter page. https://witter.com/fsgfmc

11 MedChemNet. https://www.medchemnet.com/

12 Future Medicinal Chemistry. https://www.future-science.com/loi/fmc 